\title{
Histologia e caracterização histoquímica do tubo gastrintestinal de Pimelodus maculatus (Pimelodidae, Siluriformes) no reservatório de Funil, Rio de Janeiro, Brasil
}

\author{
Clarice M. Santos ${ }^{1,2}$, Silvana Duarte ${ }^{1,3}$, Tatiana G. L. Souza², Thatiana P. Ribeiro ${ }^{2}$, \\ Armando Sales $^{2} \&$ Francisco G. Araújo ${ }^{3}$
}

1. Programa de Pós-Graduação em Biologia Animal, Instituto de Biologia, Universidade Federal Rural do Rio de Janeiro, RJ. (claricemachado@yahoo.com.br)

2. Laboratório Histologia e Embriologia Animal, IB/DBA, Universidade Federal Rural do Rio de Janeiro, Km 47 da Antiga Rodovia Rio São Paulo, 23851-970 Seropédica, RJ. (asales@ufrrj.br)

3. Laboratório de Ecologia de Peixes, IB/DBA, Universidade Federal Rural do Rio de Janeiro, RJ. (gerson@ufrrj.br)

\begin{abstract}
Histology and histochemical characterization of the digestive tract of Pimelodus maculatus (Pimelodidae, Siluriformes) in Funil reservoir, Rio de Janeiro, Brazil. Histological structures of the digestive traits of Pimelodus maculatus La Cepède, 1803 , in the Funil reservoir $\left(22^{\circ} 30^{\prime}-22^{\circ} 35^{\prime} \mathrm{S} ; 44^{\circ} 35^{\prime}-44^{\circ} 40^{\prime} \mathrm{W}\right)$ were described using haematoxilin-eosin (HE), trichome Gomori, periodic acid Schiff (PAS) and alcian blue (AB) pH 2.5 techniques. The main aim of this study was to detect the levels of glycoproteins (GPs) in the mucous tunic based in histochemical techniques and to characterize eventual alteration in the digestive tract of this species in a polluted system. Fifty-four adult individuals collected between April-2003 and July-2004 (TL=19-38 cm) were examined. The mucosa showed longitudinal folds in the buccopharyngeal cavity, with a stratified squamous epithelium. The oesophagus showed epithelium similar to buccopharyngeal cavity, with a predominance of mucous cells, which reacted strongly with the used methods. The stomach showed three regions: cardic, fundic and pyloric. The mucous tunic is continuously revested by a single cylindrical epithelium which showed positive reaction to $\mathrm{AB}$ and PAS only at the apical cells surface. The proper tunic has tubular glands that ramify gradatively, being a cellular type named oxyntopeptic, related to chloridric acid and pepsinogenic cells synthesis. The intestine showed vilosities, with the mucous tunic revested by a single cylindrical epithelium with striated planure and caliciform cells. The duodenum submucosa layer was located at the coledocum opening, as a single cylindrical epithelium lacking caliciforms cells, reacting positively with both PAS and AB. The eutrophic environment of Funil reservoir did not seem to influence morphologic patterns of the structures (oesophagus, stomach and intestine) and no modification was observed in the mucous cells activity.
\end{abstract}

KEYWORDS. Morphology, glycoproteins, fishes, Pimelodidae.

RESUMO. As estruturas teciduais do trato gastrintestinal de Pimelodus maculatus La Cepède, 1803, do reservatório de Funil (22 $30^{\prime}$ $22^{\circ} 35^{\prime} \mathrm{S} ; 4^{\circ} 35^{\prime}-44^{\circ} 40^{\prime} \mathrm{W}$ ) foram descritas através das técnicas de hematoxilina-eosina (HE), tricômico Gomori, ácido Periódico de Schiff (PAS) e alcian blue (AB) pH 2,5. Objetivou-se a detecção de glicoproteínas (GPs) na mucosa através de uma análise histoquímica e caracterização de possíveis alterações ao longo do trato digestório destes peixes neste sistema de elevado grau de alteração. Cinqüenta e quatro indivíduos adultos, coletados entre abril de 2003 e julho de 2004 (CT=19-38 cm) foram utilizados. Na cavidade bucofaríngea, a mucosa apresenta-se com pregas longitudinais e o epitélio é do tipo estratificado pavimentoso. O esôfago apresenta o mesmo tipo de epitélio da cavidade bucofaríngea, destacando-se a predominância de células mucosas que tiveram forte reação aos métodos utilizados. O estômago foi diferenciado em região cárdica, fúndica e pilórica. A mucosa é continuamente revestida por um epitélio simples cilíndrico que apresentou reação positiva ao AB e PAS somente na superfície apical das células; a lâmina própria possui glândulas tubulares que se ramificam gradativamente e consistem de um tipo celular denominado oxinticopépticas, relacionadas com a síntese de ácido clorídrico e pepsinogênio. O intestino apresenta vilosidades revestidas por um epitélio simples cilíndrico com planura estriada e células caliciformes. Na camada submucosa do duodeno foi observada a abertura do colédoco, sendo o epitélio do tipo simples cilíndrico sem células caliciformes, positivo tanto ao PAS quanto ao $\mathrm{AB}$. O ambiente eutrófico do reservatório de Funil não parece influenciar os padrões morfológicos das estruturas (esôfago, estômago e intestino) e não foram observadas modificações nas atividades das células mucosas.

PALAVRAS-CHAVE. Morfologia, glicoproteínas, peixes, Pimelodidae

A morfologia e histologia do trato gastrintestinal têm sido descritas em várias espécies de peixes (KHANnA \& Mehrotra, 1971; HARDER, 1975; KAPOOR et al., 1975; TiBbETs, 1997), despertando considerável interesse pelas amplas variações tanto na morfologia quanto nas funções, como reflexo da elevada diversidade deste grupo zoológico e suas diferentes posições na cadeia trófica. Apesar das diferenças interespecíficas no trato gastrintestinal, semelhanças estruturais básicas são comuns dentro do grupo (DiAz et al., 2003). Em algumas espécies as diferenças estão proximamente relacionadas com a natureza do hábito alimentar, tamanho do corpo e sexo (KAPOOR et al., 1975; SMith, 1989).
Pimelodus maculatus La Cepède, 1803 é um peixe de couro que habita o fundo dos ambientes aquáticos e tem ampla distribuição geográfica nas bacias hidrográficas da América do Sul (FowLER, 1954; BASILEMARTins et al., 1986b; Almeida et al., 2003). É uma espécie eminentemente onívora (HAHN et al., 1998; BASILEMartins et al., 1986a; CALlisto et al., 2002) que possui uma dieta variada, constituída por larvas de insetos, algas, moluscos, peixes e fragmentos de vegetais (BASILEMartins et al., 1986a; Lólis \& ANDRIAN, 1996; LoBÓNCerviá \& Bennemann, 2000; Callisto et al., 2002) fazendo uso dos mais diferentes recursos alimentares disponíveis no ambiente aquático (BAsiLE-MARTins et al., 1986a,b; 
HAHN et al., 1998). A detecção do alimento por esta espécie é auxiliada pela presença de dois pares de barbilhões maxilares (ALVES \& POMPEU, 2001), uma estrutura de tato do substrato e de auxílio a seus hábitos noturnos.

Menin \& Mimura (1992) compararam a anatomia funcional de três espécies neotropicais onívoras, incluindo uma do gênero Pimelodus, tendo classificado o estômago como sendo do tipo cecal e em "J", correlacionando as pregas espessas da região cárdica e fúndica à função de armazenamento de grandes volumes de alimentos. Estes autores consideraram o intestino de tamanho intermediário. Godinho et al. (1970) caracterizaram a histologia do trato digestório de Pimelodus maculatus em um ambiente oligotrófico, tendo relacionado a estrutura do aparelho digestório com o hábito alimentar.

Os peixes entram em contato mais estreito com agentes poluidores de várias maneiras, principalmente pela superfície de epitélios como a do intestino (FANTA, 1991). A ocorrência de células mucosecretoras é uma característica comum na superfície de epitélios do trato digestório de teleósteos; com as mucosubstâncias secretadas diferindo ao longo do canal alimentar dos peixes. A presença de glicoproteínas (GPs) é correlacionada com diferentes funções, como lubrificação, degradação proteolítica e inibição de microrganismos (REID et al., 1988). Neste escopo, as descrições da histologia do trato digestório são de especial interesse visando dar informações mais completas sobre todos os tipos de interferência no funcionamento de organismos vivos.

O presente trabalho visa caracterizar a histologia do trato gastrintestinal de $P$. maculatus do reservatório de Funil através de uma análise histoquímica, bem como caracterizar possíveis alterações na secreção de mucosubstâncias pelas células mucosas ao longo do trato digestório destes peixes, por estarem vivendo em estado de alteração ambiental.

\section{MATERIAL E MÉTODOS}

Exemplares de $P$. maculatus foram capturados no

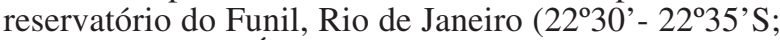
$44^{\circ} 35^{\prime}-44^{\circ} 40^{\prime} \mathrm{W}$ ). É um ambiente com área de $40 \mathrm{~km}^{2}$, onde o gradiente espacial rio-remanso pode ser observado devido à forma relativamente alongada do reservatório, em concordância com a geomorfologia do rio barrado. $\mathrm{O}$ reservatório se encontra sob forte pressão antrópica, servindo como um decantador natural de materiais em suspensão que o rio Paraíba recebe à montante, principalmente de efluentes urbano-industriais não tratados de grandes cidades (e.g. São José dos Campos, Taubaté) (MALm et al., 1989). Apesar destas condições, coletas recentes têm demonstrado a ocorrência de populações estáveis de $P$. maculatus neste reservatório.

Coletas trimestrais foram realizadas entre abril de 2003 e julho de 2004, tendo sido capturados 54 exemplares adultos com redes de emalhar. A dissecação foi realizada em campo, com os peixes tendo sido sacrificados por hipotermia. Após a tomada de peso corpóreo e do comprimento padrão, ocorreu a imediata remoção do trato digestório. Fragmentos da cavidade bucofaríngea, esôfago, estômago e intestino foram fixados por 8 horas em líquido de Bouin. Os tecidos foram desidratados em concentração crescente de etanol, clarificados em xilol e embebidos em parafina. Secções de $5 \mu \mathrm{m}$ foram coradas em hematoxilina-eosina (HE), tricrômico de Gomori, ácido periódico e reativo de Schiff (PAS) e alcian blue $(\mathrm{AB}) \mathrm{pH}$ 2,5 , visando identificar células secretoras de glicoproteínas. $\mathrm{O}$ trato digestório foi analisado através de cortes transversais e longitudinais.

\section{RESULTADOS}

Cavidade bucofaríngea. A parede é composta de túnica mucosa, submucosa, muscular e serosa. A cavidade bucofaríngea apresenta a túnica mucosa com pregas longitudinais (Fig. 1). Seu epitélio é do tipo estratificado pavimentoso, tendo sido observada a existência de células claviformes e mucosecretoras (Fig. 2). A lâmina própria é composta por um tecido conjuntivo rico em fibras colágenas. Não existem diferenças conspícuas da túnica mucosa para a submucosa, sendo esta última composta por um tecido conjuntivo frouxo, podendo ser observadas as placas dentárias (Fig. 3). As células mucosas revelaram intensa reação positiva aos métodos histoquímicos do PAS e $\mathrm{AB}$, diferentemente do encontrado nas células claviformes, que não reagiram a estes métodos.

Esôfago. A túnica mucosa do esôfago, similarmente à da cavidade bucofaríngea, apresentou pregas longitudinais e o seu revestimento é feito por um epitélio do tipo estratificado pavimentoso. O elemento com predominância neste epitélio foram as células mucosecretoras, as quais se dispuseram de forma homogênea ao longo de todo o epitélio (Fig. 4). Na região cranial do esôfago a estratificação do epitélio é mais notada, com maior número de pregas longitudinais e células claviformes quando comparado com a região caudal. A lâmina própria é formada por tecido conjuntivo frouxo. O método de coloração tricrômico de Gomori indicou ausência da muscular da mucosa e presença das fibras conjuntivas da lâmina própria e submucosa. A camada muscular é compreendida por duas camadas de fibras musculares estriadas, uma longitudinal interna e a outra circular externa. A serosa é fina, composta por epitélio simples pavimentoso. Os testes histoquímicos revelaram uma intensa reação das células mucosecretoras ao PAS (Fig. 5) e em menor extensão ao AB. A transição do esôfago para estômago é claramente percebida através da abrupta mudança do epitélio estratificado pavimentoso para o epitélio simples cilíndrico (Fig. 6).

Estômago. É dividido em regiões cárdica, fúndica e pilórica (Figs. 7-9), sendo a túnica mucosa continuamente revestida por um epitélio simples cilíndrico (Fig. 7). Sua lâmina própria possui glândulas tubulares constituídas por células chamadas de oxinticopépticas, as quais se abrem nas criptas das pregas da mucosa (Fig. 8), sendo predominantes na porção fúndica e tornando-se escassas na região pilórica.

A transição entre a lâmina própria e a túnica submucosa é demarcada pela presença de uma muscular da mucosa (Fig. 9). A túnica muscular na região cárdica e fúndica contém duas camadas de músculo liso: uma circular interna e outra longitudinal externa. Na região pilórica observaram-se três camadas, sendo uma oblíqua mais internamente. Externamente, o estômago é recoberto por uma serosa. Os testes histoquímicos revelaram uma forte reação positiva ao $\mathrm{AB}$ e PAS apenas na superfície apical das células epiteliais (Fig. 7). 
Intestino proximal, médio e distal. A mucosa apresenta vilosidades (Fig. 10). O epitélio é simples cilíndrico com planura estriada e células caliciformes mais numerosas no duodeno. Estas células se apresentam fortemente coradas
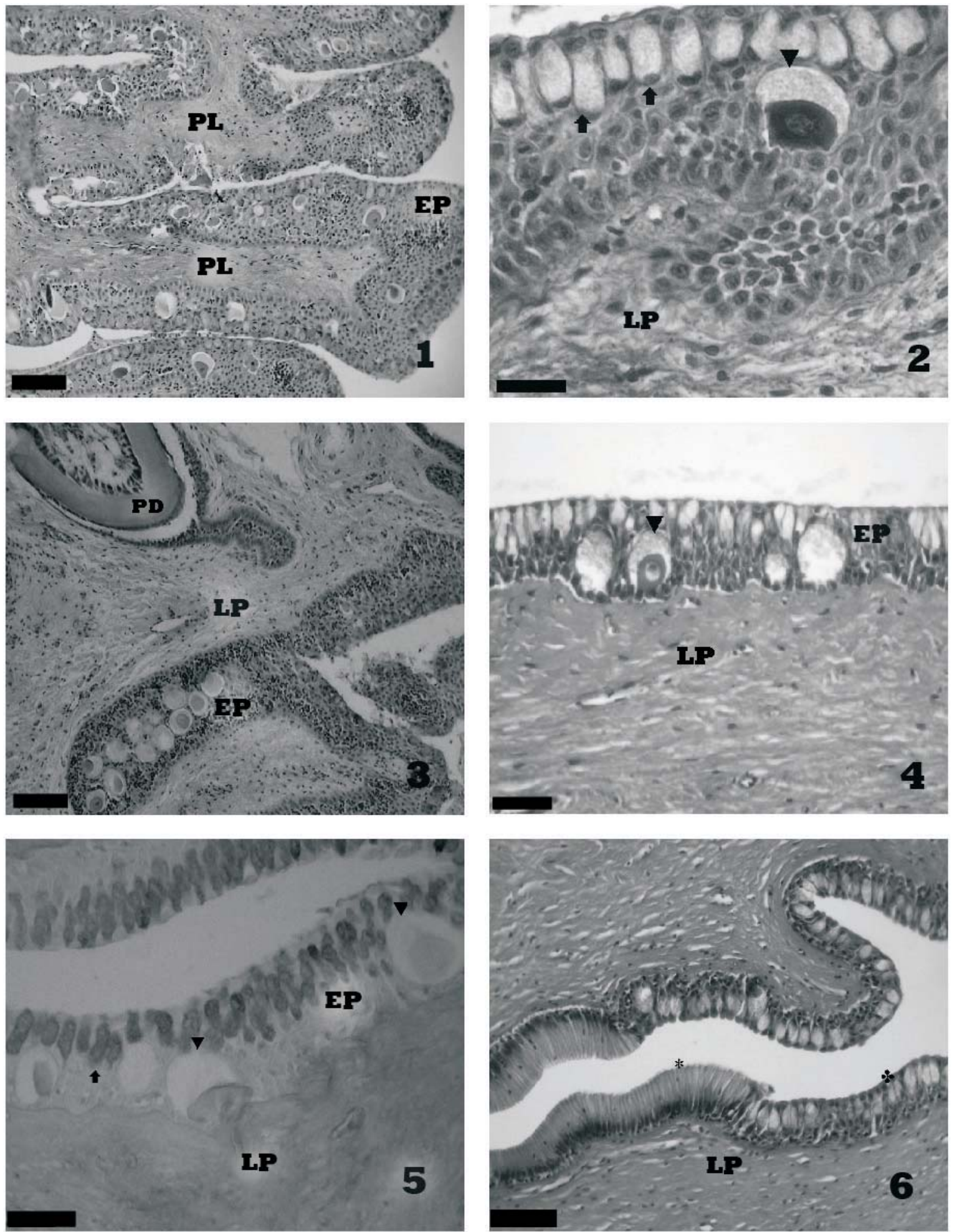

Figs. 1-6. Fotomicrografias de cortes transversais da cavidade bucofaríngea (1-3) e esôfago (4-6) de Pimelodus maculatus La Cepède, 1803. 1, Pregas longitudinais (PL), epitélio estratificado pavimentoso (EP), Hematoxilina-Eosina; 2, Epitélio com células mucosecretoras (^), claviformes ( $\mathbf{\nabla})$ e lâmina própria (LP), Tricrômico de Gomori; 3, Epitélio estratificado pavimentoso (EP), placa dentária (PD) e lâmina própria (LP); 4, Epitélio estratificado com células claviformes ( $\mathbf{\text { v }}$ e lâmina própria (LP), Tricrômico de Gomori; 5, Reação intensa das células mucosecretoras ( $)$, e ausência de marcação nas células claviformes ( $\nabla$ ) Acido Periódico de Schiff; 6, Abrupta transição do epitélio estratificado esofágico (*) para o cilíndrico simples do estômago (*), Hematoxilina-Eosina. Barras, 50 m. 
(Fig. 12). Em todo o intestino observou-se a presença de uma muscular da mucosa separando a lâmina própria da submucosa. Acamada muscular é composta por uma camada circular interna e outra longitudinal externa de músculo liso. A serosa está presente em todo o intestino, consistindo de uma camada de mesotélio.
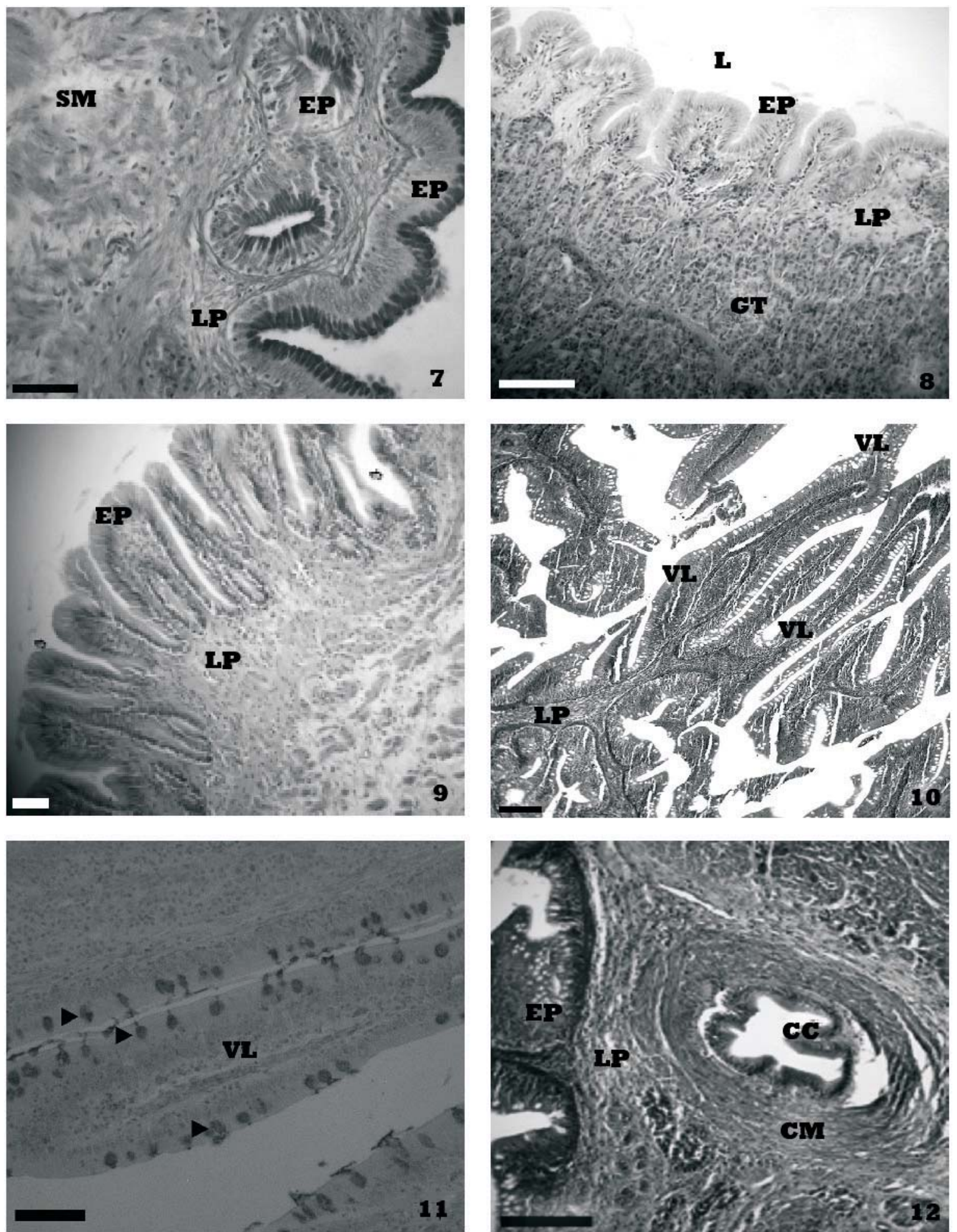

Figs. 7-12. Fotomicrografias de cortes transversais do estômago (7-9) e intestino (10-12) de Pimelodus maculatus La Cepède, 1803. 7, Região cárdica, epitélio simples cilíndrico com intensa reação na superfície da célula (EP), lâmina própria (LP) e submucosa (SM), Ácido Periódico de Schiff; 8, Região fúndica, lâmina própria com glândulas tubulares ramificadas (GT), lúmen gástrico (L), HematoxilinaEosina; 9, Região pilórica com fossetas pronunciadas $(\rightarrow)$, lâmina própria (LP), Hematoxilina-Eosina; 10, Vilosidades intestinais (VL) e lâmina própria (LP), Hematoxilina-Eosina; 11, Vilosidades intestinais (VL), epitélio simples cilíndrico com células caliciformes fortemente marcadas ( Alcian Blue; 12, Canal do colédoco (CC) com epitélio simples cilíndrico sem células caliciformes e camada muscular (CM), Tricrômico de Gomori. Barras, $50 \mu \mathrm{m}$. 


\section{DISCUSSÃO}

O padrão anatômico da mucosa da cavidade bucofaríngea de Pimelodus sp. foi descrito por MENIN \& Mimura (1992), tendo os autores inferido que este grupo de peixes se alimenta de material de origem animal com tendência à ictiofagia, deglutindo os itens sem preparação pré-digestiva. Observações de campo feitas no reservatório de Lajes, RJ, têm confirmado este padrão, com $P$. maculatus funcionando como uma espécie eminentemente onívora, porém com forte tendência à carnivoria (ARAúJo et al., 2005). O epitélio do tipo estratificado pavimentoso funciona como uma importante camada protetora contra agressões mecânicas e invasão bacteriana (HUMBERT et al., 1984). Os testes histoquímicos deste estudo mostraram forte reação das células mucosas da cavidade bucofaríngea às técnicas do PAS e AB evidenciando a presença de glicoproteínas (GPs) ácidas e neutras, o que indica o funcionamento regular destas células.

O esôfago é curto e, como na maioria dos peixes estudados, contém todas as camadas características de um órgão tubular do sistema digestório dos vertebrados: camada mucosa, submucosa, muscular e uma serosa (GodinHo, 1967; GodinHo et al., 1970; GARRIDO et al., 1993; TiBbets, 1997; AlBRECHT et al., 2001; DiAz et al., 2003). A túnica mucosa caracterizou-se pela presença de pregas longitudinais menos proeminentes do que aquelas encontradas em peixes marinhos como Engraulis anchoita Hubbs \& Marini, 1935 (DiAz et al., 2003), um provável efeito da diferenciação na dieta destas espécies, com esta última sendo filtradora planctófaga. O epitélio é do tipo pavimentoso estratificado com células mucosecretoras e claviformes. Segundo RaLPHS \& Benjamin (1992), as células claviformes, facilmente distinguidas das células mucosas, são glândulas grandes e unicelulares, secretoras de um ferormônio que induz a reação de fuga dos peixes. Este padrão pode ser uma característica do gênero, que se diferenciou do padrão encontrado para outras espécies onívoras, como Leporinus friderici Bloch, 1794 e Leporinus taeniofasciatus Britski, 1997 (ALBRECHT et al., 2001) e Oreochomis niloticus Linnaeus, 1958 (MORRISON \& WRIGHT-JR, 1999), nas quais estas células claviformes estão ausentes. As células mucosecretoras também chamadas de globosas são contínuas e abundantes. O muco secretado por elas facilita a passagem de alimentos ao longo do trato, fato observado nos onívoros $L$. friderici e L. taeniofasciatus (AlBRECHT et al., 2001) que, assim como $P$. maculatus, ingerem escamas, espinhos de nadadeiras, fragmentos de coluna vertebral de outros peixes e fragmentos queratinizados de insetos. As diferenças encontradas na região cranial e caudal do esôfago provêm do fato que estas exercem diferentes funções. A região cranial funciona como área de proteção e a caudal está envolvida com seletividade iônica e absorção de alimentos (HumBert et al.,1984).

As glândulas esofagianas já foram relatadas na lâmina própria de teleósteos (BLAKE, 1930; VEGAS-VELEZ, 1972), porém em $P$. maculatus não se observou a presença destas estruturas. A ausência da lâmina muscular da mucosa, também não encontrada em teleósteos como
Oreochromus mikiss Linnaeus, 1758 (EzEASOr, 1984) e E. anchoita (DiAz et al., 2003), facilita a passagem do alimento para o estômago, bem como a mistura deste ao ácido gástrico. Os testes histoquímicos neste estudo revelaram maior presença de glicoproteínas com hidroxilas vicinais do que glicoproteínas carboxiladas, devido à marcação mais intensa ao método do PAS. Estas GPs junto ao epitélio estratificado conferem proteção ao esôfago.

As análises demonstraram a ocorrência de uma abrupta mudança do epitélio estratificado esofágico para o epitélio simples cilíndrico do estômago. Esta passagem gastresofágica foi também descrita por GodinHo (1967) e por CACECI et al. (1997). O estômago é o órgão do sistema digestório que mais chama atenção quando está repleto, ocupando mais da metade da cavidade abdominal denotando a ampla elasticidade deste órgão, que é dividido em regiões cárdica, fúndica e pilórica, similar aos de mamíferos. No mandi-branco (Pimelodus sp.) o estômago apresenta a região pilórica pouco desenvolvida, situada ventralmente à região cárdica e dispondo-se linearmente à região fúndica, ao longo do plano sagital mediano. As regiões cárdica e fúndica possuem pregas espessas que têm a função de armazenar grande volume de alimento digerido (Menin \& MimuRA, 1992). No presente estudo também foi confirmada a existência destas regiões, assim como uma túnica muscular bastante desenvolvida na região pilórica, caracterizada por três camadas musculares (o que facilita o esvaziamento gástrico e a expulsão do alimento para o intestino anterior). Para Stroband \& VAN Der VeEN (1981), as principais funções do estômago são o armazenamento de alimentos e a defesa contra microorganismos pela produção de ácido clorídrico; a digestão protéica em ambiente de baixo $\mathrm{pH}$ seria de importância secundária. A ausência desta função digestória foi associada aos teleósteos sem estômago, que absorvem por pinocitose e digerem intracelularmente proteínas no intestino, num processo similar ao descrito em mamíferos recémnascidos.

A mucosa do estômago apresentou-se revestida por epitélio simples cilíndrico composto de células com núcleo basal e glândulas gástricas tubulares na lâmina própria. As glândulas gástricas são compostas por células oxinticopépticas que, assim como as células principais e parietais em mamíferos, relacionam-se com a síntese de ácido clorídrico e pepsinogênio. Tais glândulas foram relacionadas ao hábito alimentar (MoHsin, 1962) e atividade enzimática (Medeiros et al., 1970) de outras espécies de teleósteos tendo sido, inclusive, usadas para classificação taxonômica (KonfAN, 1966). No presente estudo não se observou reação destas glândulas com os testes histoquímicos utilizados. Os testes revelaram a presença de GPs neutras e ácidas no terço superior das células cilíndricas superficiais. Estas GPs, produzidas pelas células epiteliais, podem proteger a mucosa do ácido contido no estômago (SCOCCo et al., 1996; MorRISON \& WRIGHT-JR., 1999).

O intestino é curto, típico de peixes carnívoros, com o epitélio intestinal sendo do tipo simples cilíndrico com planura estriada e células caliciformes. Este padrão diferenciou-se do reportado por GodinHo et al. (1970) 
para P. maculatus, onde o epitélio intestinal foi do tipo estratificado prismático. As células caliciformes produzem intensa lubrificação, o que pode estar associado ao pequeno tamanho do intestino e tendências à ictiofagia da espécie, uma característica observada por MENIN \& Mimura (1992) em Pimelodus sp.

As células "rodlet cells" caracterizam-se por apresentar uma forma arqueada e já foram observadas no epitélio intestinal de O. mikiss (BIELEK, 2002), L. friderici (Albrecht et al., 2001) e Gambusia affinis Baird \& Girard, 1853 (Bullock, 1967), cuja função está associada a mecanismos de defesa. De acordo com Leino (1996) apud DiAz et al. (2005), a proliferação de "rodlet cells" no epitélio de peixes está associada à função de proteção e parece ser induzida por produção de substâncias como resultado de injúrias teciduais (parasitas, vírus) e fatores associados (fatores populacionais, concentração de íons na água). FIJAN et al. (2003) relataram a reação das "rodlet cells" como um raro achado histológico em Cyprinus carpio Linnaeus, 1758 afetado por ulcerações intestinais e enterotoxemia. Tais células, entretanto, não foram observadas no epitélio intestinal de P. maculatus. Isto pode ser uma indicação da ausência de alterações no epitélio intestinal ou a não existência destas células nesta espécie.

Na camada submucosa do duodeno foi observada a abertura do colédoco, sendo seu epitélio do tipo simples cilíndrico sem células caliciformes, positivo tanto ao PAS quanto ao $\mathrm{AB}$, o que indica a presença de uma secreção local. Externamente pode ser observada uma disposição de fibras musculares constituindo um esfíncter.

Os resultados do presente trabalho baseados na morfologia do trato digestório indicam que $P$. maculatus apresenta um padrão característico de espécie que pratica a onivoria e que o ambiente marcadamente eutrófico do reservatório de Funil não parece ter influenciado o padrão morfológico do esôfago, estômago e intestino. Igualmente, foi preservada a secreção das células mucosecretoras quando comparados com a literatura disponível para esta e outras espécies. Não foi observado qualquer indício de injúria tecidual, tais como infiltrados inflamatórios, "rodlet cells", úlceras ou lesões teciduais que pudessem ser atribuídos diretamente à exposição a poluentes. Estudos em outros órgãos poderiam ser realizados no sentido de identificar possíveis alterações morfológicas que possam ser associadas às influencias ambientais nesta espécie.

Agradecimentos. A Ilza Lucas Coelho Meirelles pelo auxílio nas técnicas laboratoriais no Laboratório de Histologia e Embriologia do Instituto de Biologia da UFRRJ. Ao Sr. Dirceu Marzulo, Paulo Sérgio Formagio, Marcos Antonio Evangelista e Maria das Neves, da Estação de Hidrobiologia e Piscicultura de Furnas, pelo suporte técnico de infra-estrutura. A FURNAS Centrais Elétricas S/A pelo apoio financeiro através do Projeto de Pesquisa \& Desenvolvimento (P\&D)/contrato $n^{\circ} 016206$ À Fundação de Amparo à Pesquisa do Rio de Janeiro - FAPERJ pela concessão de Bolsa de Doutorado à segunda autora e à CAPES-Coordenação de Aperfeiçoamento de Pessoal de Nível Superior-MEC, pela concessão de Bolsa de Mestrado à primeira autora no Programa de Pós-Graduação em Biologia Animal.

\section{REFERÊNCIAS BIBLIOGRÁFICAS}

Albrecht, M. P.; Ferreira, M. F. N. \& Caramaschi, E. P. 2001. Anatomical features and histology of the digestive tract of two related neotropical omnivorous fishes (Characiformes; Anostomidae). Journal of Fish Biology 58:419-430.
Almeida, F. S.; Sodré, D. E. \& Contel, E. P. B. 2003. Population structure analysis of Pimelodus maculatus (Pisces, Siluriformes) from the Tietê and Paranapanema rivers Brazil. Genetics and Molecular Biology 26(3):301-305.

Alves, C. B. M. \& Pompeu, P. S. 2001. Peixes do rio das Velhas: passado e presente. Belo Horizonte, Segrag. 192p.

Araúso, F. G; Andrade, C. C.; Santos, R. N.; Santos, A. F. G. N. \& SANTos, L. N. 2005. Spatial and seasonal changes in the diet of Oligosarcus hepsetus (Characiformes, Characidae) in a Brazilian reservoir. Revista Brasileira de Biologia 65(1):1-8.

Basile-Martins, M. A.; Cipólli, M. N. \& Godinho, H. M. 1986a. Alimentação do mandi, Pimelodus maculatus Lacépède, 1803 (Osteichthyes, Pimelodidae), de trechos dos rios Jaguari e Piracicaba, São Paulo-Brasil. Boletim do Instituto de Pesca 13(1): 17-29.

Basile-Martins, M. A.; Godinho, H. M.; Narahara, M. Y.; FenerichVerani, N. \& Cipólli, M. N. 1986b. Estrutura da população e distribuição espacial do mandi, Pimelodus maculatus Lacépède, 1803 (Osteichthyes, Pimelodidae), de trechos dos rios Jaguari e Piracicaba, São Paulo, Brasil. Boletim do Instituto de Pesca 13(1): 169-184.

BieleK, E. 2002. Rodlet cells in teleosts: new ultrastructural observations on the distribution of the cores in trout (Oncorhynchus mykiss, Salmo trutta L.). Journal of Submicroscopic Cytology and Pathology 34(3):271-278.

BlaKe, I. H. 1930. Studies on the comparative histology of the digestive tube of certain Teleostes fishes. Journal of Morphology 50:39-70.

Bullock W. L. 1967. The intestinal histology of the mosquito fish, Gambusia affins (Baird and Girard). Acta Zoologica 48: 1 - 17 .

Caceci, T.; El-Habback, H. A.; Sмith, S. A. \& Sмith, B. J. 1997. The stomach of Oreochromis niloticus has three regions. Journal of Fish Biology 50:939-952.

Callisto, M.; Vono, V.; Barbosa, F. A. R. \& SAnteiro, S. M. 2002. Chironomidae as a food resource for Leporinus amblyrhyncus (Teleostei: Characiformes) and Pimelodus maculatus (Teleostei: Siluriformes) in a Brazilian reservoir. Lundiana 3(1):67-73.

Diaz, A. O.; García, A. M.; Devincenti, C. V. \& Goldemberg, A. L. 2003. Morphological and histochemical characterization of the mucosa of the digestive tract in Engraulis anchoita. Anatomia, Histologia, Embryologia: Journal of Veterinary Medicine, Série C 32:341-346.

2005. Ultrastructure and histochemical study of glycoconjugates in the gills of the white croaker (Micropogonias furnieri). Anatomia, Histologia, Embryologia: Journal of Veterinary Medicine, Série C 34:117-122.

EzEASor, D. N. 1984. Light and electron microscopic studies on the oesophageal epithelium of the rainbow trout Salmo gairdneri. Anatomisher Anzeiger 155:71-83.

Fanta, E. 1991. Ação de poluentes sobre tecidos. In: SAntos, H. S. L. org. Histologia de peixes. Jaboticabal, FCAV-UNESP. p.32-37.

Fijan, N.; Petrinec, Z. \& Grabarevic, E. 2003. Intestinal ulceration and enterotoxemia in carp: case histology and implications. In: Annual Eastern Fish Health Workshop $28^{\text {th }}$, Getysburg. Proceedings... Getysburg. USGS. p. 53.

Fowler, H. W. 1954. Os peixes de água doce do Brasil. Arquivos Zoológica 2(1-12):1-400.

Garrido M. V.; Nuñez Torres, M. I. \& Abaurrea, M. A. 1993. Histological, histochemical and ultrastructural analysis of the gastric mucosa in Oncorhynchus mykiss. Aquaculture 115: $121-132$.

GodinHo, H. 1967. Estudos anatômicos sobre o trato alimentar de um Siluroidei Pimelodus maculatus Lacépède, 1803. Revista Brasileira de Biologia 27(4):425-433.

Godinho, H.; Tokimaru, M. \& Ferri, A. G. 1970. Histologia do trato digestivo de Pimelodus maculatus Lacépède, 1803 (pisces, Siluroidei). Revista Brasileira de Biologia 30(4):583-593.

Hahn, N. S.; Agostinho, A. A.; Gomes, L. C. \& Bini, L. M. 1998. Estrutura trófica da ictiofauna do reservatório de Itaipu ParanáBrasil nos primeiros anos de sua formação. Revista Interciência 23(4):299-305. 
Harder, W. 1975. The digestive tract. In: Harder, W. ed. Anatomy of fishes. Stuttgart, Schweizerbart'sche Verlagsbuchhandlung (Nägele, Obermiller). v.1, p. 159-164.

Humbert, W.; Kirsch, R. \& Meister, M. F. 1984. Scanning electron microscopic study of the oesophageal mucous layer in the eel, Anguilla anguilla. Journal of Fish Biology 25(1):117-122.

Kapoor, B. G.; Smith, H. \& Verighina, I. A. 1975. The alimentary canal and digestion in teleosts. Advance in Marine Biology 63:301-308

Khanna, S. S. \& Mehrotra, I. F. 1971. Morphology and histology of teleostean intestine. Anatomisher Anzeiger 129:1-18.

Konfan, E. 1966. Beitrag zur vergleichenden mikroskopischen anatomie der verdaungsröhre der fishe. Acta Facultatis Rerum Naturalium Universitatis Comenianae Zoologia 13:259-267.

Lobón-Cerviá, J. \& Bennemann, S. 2000. Temporal trophic shifts and feeding diversity in two sympatric, neotropical, omnivorous fishes: Astyanax bimaculatus and Pimelodus maculatus in Rio Tibagi (Paraná, Southern Brazil). Archives fuer Hydrobiologie 149(2):285-306.

Lólis, A. A. \& Andrian, I. F. 1996. Alimentação de Pimelodus maculatus Lacépède, 1803 (Siluriformes, Pimelodidae) na planície de inundação do Alto Rio Paraná, Brasil. Boletim do Instituto de Pesca 23(1):23-28.

Malm, O. Pfeiffer, W. C; Fiszman, M. \& Azcue, J. M. P. 1989. Heavy metal concentrations and availability in the bottom sediments of the Paraíba do Sul - Guandu river system, RJ, Brazil. Environmental Technology Letters 10:675-680.

Medeiros, L.; Ferri, S.; Longhi, L. \& Worsman, T. 1970. Histochemical study of protein in epithelial tissue of the digestive tract of Pimelodus maculatus Lacepéde, 1803. Acta Histochemica 37(1):113-117.
Menin, E. \& Mimura, O. M. 1992. Anatomia funcional comparativa do estômago de três peixes Teleostei de hábito alimentar onívoro. Revista Ceres 39(223):233-260.

Morrison, C. M. \& Wright JR., J. R. 1999. A study of the histology of the digestive tract of the Nile tilapia. Journal of Fish Biology 54:597-606.

Mohsin, S. M. 1962. Comparative morphology and histology of the alimentary canals in certain groups of indian teleostes. Acta Zoologica 43:79-133.

Ralphs, J. R. \& Benjamin, M. 1992. Chondroitin and keratan sulphate in the epidermal club cells of teleosts. Journal of Fish Biology 40:473-475.

Reid, P. E.; Volz, D.; Cho, K. Y. \& Owen, D. A. 1988. A new method for the histochemical demonstration of O-acyl suggars in human colonic epithelial glycoproteins. The Histochemical Journal 20:510-518.

Scocco, P.; Ciccarelli, P. \& Menghi, G. 1996. Glycohistochemistry of the Tilapia spp. stomach. Journal of Fish Biology 49:584-593.

Smith, L. S. 1989. Digestive functions in teleosts fishes In: Halver, J. E. eds. Fish nutrition. San Diego, Academic. p.331-421.

Stroband, H. W. J. \& Van Der Veen, F. H. 1981. Localization of protein absorption during transport of food in the intestine of grasscarp Ctenopharyngodon idella. Journal of Experimental Zoology 218:149-156.

Tibbets I. R. 1997. The distribution and function of mucous cells and their secretions in the alimentary tracty of Arrhamphus sclerolepis Krefftii. Journal of Fish Biology 50:809-820.

Vegas-Velez, M. 1972. La structure histologique typique du tube digestif des poissons télèosteens. Tethys 4:163-174.

Recebido em agosto de 2005. Aceito em junho de 2007. ISSN 0073-4721

Artigo disponível em: www.scielo.br/isz 